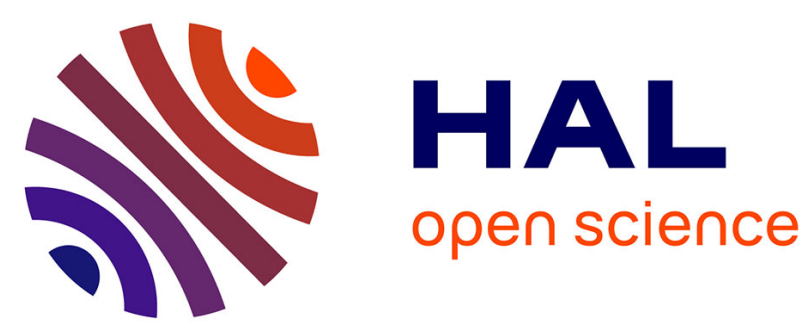

\title{
One-Pot Synthesis of Pegylated Fluorescent Nanoparticles by RAFT Miniemulsion Polymerization Using a Phase Inversion Process.
}

Chloé Grazon, Jutta Rieger, Rachel Méallet-Renault, Gilles Clavier, Bernadette Charleux

\section{To cite this version:}

Chloé Grazon, Jutta Rieger, Rachel Méallet-Renault, Gilles Clavier, Bernadette Charleux. OnePot Synthesis of Pegylated Fluorescent Nanoparticles by RAFT Miniemulsion Polymerization Using a Phase Inversion Process.. Macromolecular Rapid Communications, 2011, 32 (9-10), pp.699-705. 10.1002/marc.201100008 . hal-00598359

\section{HAL Id: hal-00598359 https://hal.science/hal-00598359}

Submitted on 9 Nov 2021

HAL is a multi-disciplinary open access archive for the deposit and dissemination of scientific research documents, whether they are published or not. The documents may come from teaching and research institutions in France or abroad, or from public or private research centers.
L'archive ouverte pluridisciplinaire HAL, est destinée au dépôt et à la diffusion de documents scientifiques de niveau recherche, publiés ou non, émanant des établissements d'enseignement et de recherche français ou étrangers, des laboratoires publics ou privés. 


\section{One-pot Synthesis of Pegylated Fluorescent Nanoparticles by RAFT Miniemulsion Polymerization using a Phase Inversion Process ${ }^{\text {a }}$}

Chloé Grazon, Jutta Rieger, Rachel Méallet-Renault, Gilles Clavier*, Bernadette Charleux*

Chloé Grazon, Dr. R. Méallet-Renault, Dr. G. Clavier

PPSM, ENS Cachan, CNRS, UniverSud, 61 av President Wilson, F-94230 Cachan (France)

E-mail: gilles.clavier@ppsm.ens-cachan.fr

Dr. J. Rieger

Laboratoire de Chimie des Polymères (LCP), Université Pierre et Marie Curie (UPMC) and CNRS, UMR 7610, 4 place Jussieu, Tour 44-54, 75252 Paris Cedex 05 (France)

Prof. B. Charleux

Université de Lyon, Univ. Lyon 1, CPE Lyon, CNRS UMR 5265, C2P2, Team LCPP Bat 308F, 43 Bd du 11 novembre 1918, 69616 Villeurbanne (France)

E-mail: bernadette.charleux@lcpp.cpe.fr

Summary:

Water-soluble and fluorescent core-shell nanoparticles (FNP) are synthesized in a miniemulsion RAFT polymerization and are shown to respond to $\mathrm{pH}$. The particles are obtained from a hydrophilic PEO- $b$-PAA macromolecular RAFT agent which is blockextended with styrene and a fluorescent BODIPY monomer. A miniemulsion is then formed with the residual hydrophobic monomers. After completion of the polymerization, FNP of approximately $60 \mathrm{~nm}$ in diameter are obtained. The fluorescence of the BODIPY dye in the particles is found to remain ( 0.2 quantum yield). The particles can be precipitated in acidic $\mathrm{pH}$ and redispersed upon addition of base without loss of their integrity or noticeable rearrangement.

\section{Introduction}

In the last decade, fluorescent molecules and nanoobjects have received increasing interest for their high potential in biology and biochemistry. They are especially attractive for 
sensing, imaging and biomedical applications. ${ }^{[1]}$ Usually, organic fluorophores are hydrophobic compounds and as such not soluble in water-based biological medias. They can be modified with water solubilizing groups but, most of the time, at the expense of the fluorescence quantum yield which drops dramatically. Further, the toxicity of these compounds is not well known. An appealing alternative is to incorporate them in organic or inorganic (nano-)particles that are water-dispersible. One approach relies on the encapsulation of a dye in the hydrophobic core of a polymeric nanoparticle, using a polymerization process in heterogeneous dispersed aqueous media, especially miniemulsion. ${ }^{[2]}$ In this process, ${ }^{[3]}$ the hydrophobic fluorophore is initially dissolved in the organic monomer droplets and during polymerization encapsulated in the nanoparticles. Generally, quite high surfactant concentrations are necessary in order to stabilize the monomer droplets dispersions in the aqueous phase, which are converted upon polymerization into solid particles (also stabilized by the surfactant). In addition, miniemulsion polymerization usually requires the use of hydrophobic costabilizers such as hexadecane or hydrophobic polymer chains to avoid the Ostwald ripening between monomer droplets. Unfortunately, the necessity to use additives, especially surfactants and co-stabilizers, might have detrimental effects when biological applications are targeted. In addition, leaking of the physically entrapped fluorescent dye out of the fluorescent nanoparticle (FNP) is also an issue.

Recent works aim thus at covalently incorporating the fluorophore in the FNP. Controlled radical polymerization (CRP), especially atom transfer radical polymerization (ATRP) and reversible addition-fragmentation transfer (RAFT) polymerization, has proved to be an easy and efficient tool to achieve polymer chains that are functionalized by fluorescent dyes either at their $\alpha$-end (using functional initiators) ${ }^{[4]}$ or along the polymer backbone by copolymerization with fluorescent monomers. ${ }^{[5]}$ Fluorescent amphiphilic block copolymer can then be self-assembled in a solvent which is selective of one of the blocks (co-solvent method $)^{[6]}$ to form fluorescent micelles which do not suffer from dye leaking. ${ }^{[7]}$ However, this 
approach requires the use of organic co-solvents, is time consuming and yields low concentrated aqueous dispersions. As new methods are thus required to reach FNP, the miniemulsion copolymerization of a fluorophore with a conventional monomer ${ }^{[8]}$ appears a more successful option to achieve auto-stabilized fluorescent nanoparticles in a minimum of steps.

Parallel researches in latex synthesis have allowed combining CRP with heterogeneous polymerization process such as miniemulsion. Thanks to CRP techniques, one can avoid the use of low molecular weight amphiphiles by using macromolecular chain transfer agents which may act simultaneously as emulsion stabilizers and as control agents. Indeed, the aqueous miniemulsion RAFT polymerization of styrene has been successfully achieved using either poly(ethylene oxide)- $b$-poly(styrene) (PEO- $b$-PS), or poly(acrylic acid)$b$-poly(styrene) (PAA- $b$-PS) amphiphilic macromolecular RAFT (macroRAFT) agents. ${ }^{[9]}$

In our study, we chose a PEO- $b-\mathrm{PAA}-\mathrm{TTC}-\mathrm{C}_{12}$ (TTC: trithiocarbonate, Scheme S2) macroRAFT agent in order to reach pegylated biocompatible ${ }^{[10]}$ and $\mathrm{pH}$-sensitive ${ }^{[11]}$ autostabilized fluorescent nanoparticles. As such they should be able to control the copolymerization of styrene with a fluorescent monomer in miniemulsion. We propose a novel synthesis strategy to obtain fluorescent nanoparticles of well-defined chain lengths and sizes, via a miniemulsion process in water based on a phase inversion, ${ }^{[12]}$ using BODIPY methacrylate (BDPMA) and styrene (S) as monomers. Hence, all the chemicals introduced in our miniemulsion process are covalently linked within the final FNP ensuring that no posttreatment of the nanoobjects is necessary to remove any undesirable toxic leftovers.

BODIPY was chosen as a hydrophobic fluorophore, ${ }^{[13]}$ as it shows attractive spectroscopic characteristics such as emission spectra tuneable from green to red and high fluorescence quantum yields. To our knowledge only few examples on the copolymerization of BODIPY monomers by free radical polymerization ${ }^{[14]}$ have been reported and only one by RAFT in homogeneous media. ${ }^{[15]}$ 


\section{Experimental Section}

\section{Materials}

2,4-Dimethyl-3-ethylpyrrol (97\%, Aldrich, kryptopyrrol), boron trifluoride diethyletherate (2M in diethyl ether, Aldrich), 4-hydroxybenzaldehyde (98\%, Aldrich), tetrachloro-1,4benzoquinone (99\%, Aldrich, Chloranil), N,N-diisopropylethylamine (99,5\%, Sigma-Aldrich, DIPEA), 1,8-diazobicyclo[5,4,0]undec-7-ene ( $\geq 98 \%$, Fluka, DBU), trifluoroacetic acid (99\%, Sigma Aldrich, TFA), acrylic acid (anhydrous, 99\%, Aldrich), 4,4'-azobis(4-cyanopentanoic acid) (Aldrich, ACPA), (trimethylsilyl)diazomethane (2M solution in diethyl ether, Aldrich) were used as received. Solvents (Carlo Erba) were of synthetic grade and purified according to standard procedures. 2,2'-Azobis(2-methylpropionitrile) (98\%, Sigma, AIBN) was recrystallised from chloroform and few drops of petroleum ether. Styrene $(\geq 99 \%$, Sigma Aldrich) and methacryloyl chloride (97\%, Fluka) were distilled under reduced pressure. Phosphate buffered saline $1 \times$ was prepared from dry powder diluted in distilled water (Sigma, PBS). Silica gel $60 \AA$ (70-200 mm porosity) was bought from SDS. Distilled water adjusted with aqueous sodium hydroxide solution $(1 \mathrm{M})$ to a $\mathrm{pH}$ comprised between 12 and 12.5 was used for nanoparticles synthesis. The BODIPY phenol (Scheme S1, 1) ${ }^{[16]}$, molecular RAFT agent S-1-dodecyl-S'-( $\alpha, \alpha^{\prime}$-dimethyl- $\alpha$ '-acetic acid) trithiocarbonate (TTCA) ${ }^{[17]}$ and the TTCA-based macroRAFT agents PEO-TTC-C $12\left(M_{\mathrm{n}}=2420 \mathrm{~g} / \mathrm{mol}\right.$, end-functionnality $>$ $95 \%)^{[18]}$ were synthesized as described elsewhere. Synthetic schemes are available in the supporting information.

\section{Synthesis of BODIPY methacrylate 2}

BODIPY phenol (1.2 mmol, $475 \mathrm{mg})$ is dissolved in $50 \mathrm{~mL}$ of anhydrous dichloromethane, under argon equipped with a $\mathrm{CaCl}_{2}$ moisture trap. Then DBU (2 equiv., $2.4 \mathrm{mmol}, 365 \mathrm{mg}$ ) is 
slowly added with a syringe to the solution and methacryloyl chloride (1.5 equiv., $1.8 \mathrm{mmol}$, $190 \mathrm{mg}$ ) is added to the dark solution. The mixture is stirred at room temperature during $24 \mathrm{~h}$, until disappearance of the BODIPY phenol trace on TLC. The mixture is concentrated and the residue purified by chromatography on silica gel (dichloromethane/petroleum ether: 70/30), affording $432 \mathrm{mg}$ of product $\left(78 \%\right.$ yield). $\mathrm{mp}=186^{\circ} \mathrm{C}$.

${ }^{1} \mathrm{H} \mathrm{NMR}\left(400 \mathrm{MHz}, \mathrm{CDCl}_{3}, \delta\right): 7.32\left(\mathrm{~d}, 2 \mathrm{H}, J_{H c-H d}=8.7 \mathrm{~Hz}, H_{c}\right), 7.27\left(\mathrm{~d}, 2 \mathrm{H}, J_{H d-H c}=8.7 \mathrm{~Hz}\right.$, $\left.H_{d}\right), 6.39\left(\mathrm{~s}, 1 \mathrm{H}, H_{a}\right), 5.80\left(\mathrm{~s}, 1 \mathrm{H}, H_{a}\right), 2.52\left(\mathrm{~s}, 6 \mathrm{H}, H_{e}\right), 2.29\left(\mathrm{q}, J_{H f-H g}=7.6 \mathrm{~Hz}, 4 \mathrm{H}, H_{f}\right), 2.08$ $\left(\mathrm{s}, 3 \mathrm{H}, H_{b}\right), 1.33\left(\mathrm{~s}, 6 \mathrm{H}, H_{h}\right), 0.97\left(\mathrm{t}, J_{H g-H f}=7.6 \mathrm{~Hz}, 6 \mathrm{H}, H_{g}\right) \mathrm{ppm} .{ }^{13} \mathrm{C} \mathrm{NMR}\left(100 \mathrm{MHz}, \mathrm{CDCl}_{3}\right.$, $\delta): 165.69(\mathrm{O}-C \mathrm{R}=\mathrm{O}), 154.01$ ( $C_{q}$, pyr. $), 151.44\left(C_{q}\right.$, ar.), $139.22\left(C_{q}\right.$, pyr. $), 138.45$ ( $C_{q}$, ar. $)$, 135.78 ( $C_{q}$, ar.), 133.32 ( $C_{q}$, vin. $), 133.00$ ( $C_{q}$, pyr. $), 130.90\left(C_{q}\right.$, pyr. $), 129.53\left(C_{2 \mathrm{~d}}\right), 127.68$ $\left(C \mathrm{H}_{\mathrm{a}, \mathrm{a}^{\prime}}\right), 122.58\left(\mathrm{CH}_{2 \mathrm{c}}\right), 18.46\left(C \mathrm{H}_{\mathrm{b}}\right), 17.15\left(C \mathrm{H}_{\mathrm{f}}\right), 14.68\left(\mathrm{CH}_{\mathrm{g}}\right), 12.60\left(C \mathrm{H}_{\mathrm{h}}\right), 11.92\left(C \mathrm{H}_{\mathrm{e}}\right) \mathrm{ppm}$. ${ }^{19} \mathrm{~F}$ NMR $\left(376 \mathrm{MHz}, \mathrm{CDCl}_{3}\right): \delta=-145.68\left(\mathrm{q}, \mathrm{J}_{\mathrm{F}-\mathrm{B}}=32.9 \mathrm{~Hz}\right) \mathrm{ppm} .{ }^{11} \mathrm{~B}$ NMR $(128 \mathrm{MHz}$, $\left.\mathrm{CDCl}_{3}\right): \delta=-0.15\left(\mathrm{t}, \mathrm{J}_{\mathrm{B}-\mathrm{F}}=32.9 \mathrm{~Hz}\right) \mathrm{ppm}$. HRMS (ESI) $m / z[\mathrm{M}+\mathrm{Na}]^{+}$calcd for $\mathrm{C}_{27} \mathrm{H}_{31} \mathrm{BF}_{2} \mathrm{~N}_{2} \mathrm{NaO}_{2}$ 487.2344; found 487.2349.

\section{Synthesis of macroRAFT agents (Scheme S2)}

PEO- $b$-PAA-TTC- $\mathrm{C}_{12}$ macroRAFT agents are synthesised in 1,4-dioxane at $70^{\circ} \mathrm{C}$ under nitrogen atmosphere. In a typical experiment, PEO-TTC- $\mathrm{C}_{12}$ macroRAFT agent $(0.5 \mathrm{mmol}$, $\left.1.21 \mathrm{~g}, M_{\mathrm{n}}=2420 \mathrm{~g} / \mathrm{mol}\right)$, acrylic acid $(10 \mathrm{mmol}, 720 \mathrm{mg})$ and DMF (as an internal reference for the ${ }^{1} \mathrm{H}$ NMR determination of the monomer consumption in deuterated chloroform ) (2 mmol, $146 \mathrm{mg}$ ) are dissolved in $4.9 \mathrm{~mL}$ of 1,4-dioxane at room temperature. Then, $0.1 \mathrm{~mL}$ of a $0.33 \mathrm{M}$ solution of ACPA in 1,4-dioxane is added. The mixture is purged with nitrogen for 30 min in an ice bath, then placed in an oil bath thermostated at $70^{\circ} \mathrm{C}$ to initiate the polymerization. After $90 \mathrm{~min}$, the reaction is stopped by immersion of the flask in iced water. The monomer conversion is determined by ${ }^{1} \mathrm{H}$ NMR in $\mathrm{CDCl}_{3}$ and is $66 \%$. The copolymer was dried under reduced pressure in order to remove the residual acrylic acid monomer. The composition of the 
copolymer is found to be $\mathrm{PEO}_{44}-b-\mathrm{PAA}_{13}-\mathrm{TTC}-\mathrm{C}_{12}\left(M_{\mathrm{n}}\right.$ th $=3350, M_{\mathrm{n} \mathrm{SEC}}=4120, M_{\mathrm{w}} / M_{\mathrm{n}}=1.04$, PS calibration) $)^{[19]}$, where 13 stands for the $\mathrm{DP}_{\mathrm{n}}$ of the PAA block, determined by ${ }^{1} \mathrm{H}$ NMR. Another macroRAFT agent possessing 10 PAA units $\left(\mathrm{PEO}_{44}-b-\mathrm{PAA}_{10}-\mathrm{TTC}_{-} \mathrm{C}_{12}\right)$ was synthesized following the same protocol $\left(M_{\mathrm{n}}\right.$ th $=3140, M_{\mathrm{n} \mathrm{SEC}}=4170 \mathrm{~g} / \mathrm{mol}, M_{\mathrm{w}} / M_{\mathrm{n}}=1.07, \mathrm{PS}$ calibration). ${ }^{[19]}$

\section{Synthesis of fluorescent nanoparticles}

RAFT polymerization of styrene and BODIPY methacrylate is performed in the presence of living poly(ethylene oxide)- $b$-poly(acrylic acid), PEO- $b$-PAA $13-T T C-C_{12}$, copolymers as macroRAFT agent in a one-pot phase inversion process. In a typical experiment, PEO- $b$-PAA macroRAFT $\left(4.2 \times 10^{-5} \mathrm{~mol}, 140 \mathrm{mg}\right)$ is dissolved in a mixture of styrene $\left(6.6 \times 10^{-3} \mathrm{~mol}, 680\right.$ $\mathrm{mg}), \operatorname{AIBN}\left(2.3 \mathrm{mg}, 1.4 \times 10^{-5} \mathrm{~mol}\right)$ and BDPMA $\left(1.3 \times 10^{-4} \mathrm{~mol}, 59 \mathrm{mg}\right)$, in a septum-sealed flask. The mixture is purged with argon for $30 \mathrm{~min}$ in an ice bath, and then placed in an oil bath thermostated at $80^{\circ} \mathrm{C}$ to initiate polymerization. After $70 \mathrm{~min}$, the reaction is stopped by immersion of the flask in iced water. The conversion is determined by gravimetry. To the cold organic mixture, $5 \mathrm{~mL}$ of basic water $(\mathrm{pH}=12.5)$ is added. An ultrasonic horn (Bandelin electronics, Sonoplus HD 2200) is then placed in the biphasic mixture cooled down in an ice bath and powered at $130 \mathrm{~W}$ for 10 minutes. After the miniemulsion formation, the $\mathrm{pH}$ decreased to 11 . The miniemulsion is purged with argon for $30 \mathrm{~min}$ in an ice bath, and then placed in an oil bath thermostated at $80^{\circ} \mathrm{C}$ to re-initiate polymerization. Sampling is performed at regular time intervals and monomer conversions are determined by gravimetry for styrene (Equation S1) and SEC using the UV-visible detection for BDPMA (Equation S2).

\section{Instrumentation}

${ }^{1} \mathrm{H},{ }^{13} \mathrm{C},{ }^{19} \mathrm{~F}$ and ${ }^{11} \mathrm{~B}$ NMR spectra were recorded in $\mathrm{CDCl}_{3}$ on a JEOL ECS (400 MHz) spectrometer. All chemical shifts are referenced to $\mathrm{Me}_{4} \mathrm{Si}$ (TMS). Coupling constants (J) 
values are given in Hz. In order to monitor the conversion of acrylic acid (AA), DMF (7.95

ppm) was used as internal standard and conversions were determined by the relative decrease of the acrylic acid signals at 6.35, 6.04 and 5.80 ppm to DMF.

High resolution mass spectroscopy was performed at the CNRS Imagif platform (Waters spectrometer).

Melting point was measured with a Kofler melting-point apparatus and is uncorrected. $\mathrm{pH}$ measurement were performed using a glass electrode connected to a PHM210 Standard $\mathrm{pH}$ meter from Meterlab.

The number-average molar mass $\left(M_{\mathrm{n}}\right)$, the weight-average molar mass $\left(M_{\mathrm{w}}\right)$, and the molar mass distribution (polydispersity index $M_{\mathrm{w}} / M_{\mathrm{n}}$ ) were determined by size exclusion chromatography (SEC) using THF as an eluent at a flow rate of $1 \mathrm{~mL} \cdot \mathrm{min}^{-1}$. For analytical purposes, the acidic functions of the poly(ethylene oxide)- $b$-(acrylic acid) and poly(ethyleneoxide)- $b$-poly(acrylic acid)- $b$-poly(styrene-co-BODIPY methacrylate) copolymers were turned into methyl esters. The block copolymers were recovered by drying of the aqueous suspensions. After dissolution in a $\mathrm{THF} / \mathrm{H}_{2} \mathrm{O}$ mixture and acidification of the medium with a $1 \mathrm{M} \mathrm{HCl}$ solution, they were methylated using an excess of trimethylsilyldiazomethane. Polymers were analyzed at a concentration of $5 \mathrm{mg} \cdot \mathrm{mL}^{-1}$ in THF after filtration through 0.45 $\mu \mathrm{m}$ pore size membrane. The SEC apparatus is equipped with a Viskotek VE 5200 automatic injector and two columns thermostated at $40^{\circ} \mathrm{C}$ (PSS, SDV, linear M, $8 \mathrm{~mm} \times 300 \mathrm{~mm}$, bead diameter : $5 \mu \mathrm{m}$ ). Detection was made with a differential refractive index detector (LCD analytical Refracto Monitor IV) and a UV-vis. detector (Waters 484 Tunable Absorbance Detector). The Viscotek OmniSEC software was used for data analysis and the relative $M_{\mathrm{n}}$ and $M_{\mathrm{w}} / M_{\mathrm{n}}$ were calculated with a calibration curve based on polystyrene standards (from Polymer Laboratories).

The z-average particle diameter (named $D_{\mathrm{h}}$ ) and the particle size distribution (dispersity factor, named $\sigma$ ), were determined by dynamic light scattering (DLS) of the diluted aqueous 
dispersions, at an angle of $90^{\circ}$ at $20^{\circ} \mathrm{C}$, with a Zetasizer Nano S90 from Malvern, using a 4 $\mathrm{mW}$ He-Ne laser at $633 \mathrm{~nm}$. A value of poly below 0.1 is characteristic of a narrow particle size distribution. All calculations were performed using the Nano DTS software. Samples analysed in PBS were filtered through $0.45 \mu \mathrm{m}$ before analysis. The hydrodynamic diameter was further used for determination of the number of particles, $N_{\mathrm{p}}$.

Conventional transmission electron microscopy (TEM) was performed on a JEOL JEM CX II UHR microscope operating at $100 \mathrm{keV}$ and equipped with a Keen View CCD camera from Soft Imaging System (Olympus) calibrated with three polystyrene particle samples (PELCO 610-SET - 91, 300, and $482 \mathrm{~nm}$, Ted Pella Inc.). The acquisition was done with the iTEM software from Soft Imaging System (Olympus). The samples were diluted in water prior to analysis and then deposited on a carbon-coated copper grid.

UV-visible spectra were recorded on a Varian Cary (Palo Alto, CA USA) double beam spectrometer using a $10 \mathrm{~mm}$ path quartz cell from Thuet (Bodelsheim, France). Excitation and emission spectra were measured on a SPEX Fluoromax-3 (Horiba Jobin-Yvon). A right-angle configuration was used. Optical density of the samples was checked to be less than 0.1 to avoid reabsorption artifacts. The fluorescence decay curves were obtained with a timecorrelated single-photon-counting method using a titanium-sapphire laser ( $82 \mathrm{MHz}$, repetition rate lowered to $4 \mathrm{MHz}$ thanks to a pulse-peaker, 1 ps pulse width, a doubling crystals is used to reach $495 \mathrm{~nm}$ excitation) pumped by an argon ion laser from Spectra Physics (Mountain View, CA USA). The Levenberg-Marquardt algorithm was used for non-linear least square fit as implemented in the Globals software (Globals Unlimited, Villa Grove, USA). In order to estimate the quality of the fit, the weighted residuals were calculated. In the case of single photon counting, they are defined as the residuals, i.e. the difference between the measured value and the fit, divided by the square root of the fit. $\chi^{2}$ is equal to the variance of the weighted residuals. A fit was said appropriate for $\chi^{2}$ values between 0.8 and 1.2 . 


\section{Results and Discussion}

The FNP particles' synthesis (Scheme 1, Scheme S2, Table S1) is performed in a one-pot, two-step process: the first step consists in the bulk copolymerisation at $80^{\circ} \mathrm{C}$ of styrene and $2 \mathrm{~mol} \%$ of BDPMA in the presence of a double hydrophilic macroRAFT agent $\mathrm{PEO}_{44}-b$-PAA $13-\mathrm{TTC}-\mathrm{C}_{12}{ }^{[20]}$ in order to obtain an amphiphilic surface-active triblock copolymer possessing a short hydrophobic block, $\mathrm{PEO}_{44}-b$-PAA $13-b-\mathrm{P}(\mathrm{S}-c o-\mathrm{BDPMA})_{25}$-TTC$\mathrm{C}_{12}$. The polymerization is stopped by cooling after $70 \mathrm{~min}$ at $16 \%$ of conversion.

In a second step, basic water ( $\mathrm{pH} 12.5)$ was added to this medium at room temperature (composed of formed amphiphilic macroRAFT agent, residual monomer (84\%) and initiator) and ultra-sound treatment in an ice bath allowed the formation of nanosized monomer droplets stabilized by the amphiphilic negatively charged macroRAFT agent obtained in the first step (phase inversion process). Then the RAFT polymerization was reinitiated in the monomers droplets by simple heating to $80^{\circ} \mathrm{C}$. In absence of surfactant, the hydrophobic block is thus chain-extended in a miniemulsion process yielding aqueous dispersions ( $\mathrm{pH} 11)$ of self-stabilized fluorescent nanoparticles (FNP). ${ }^{[21]}$

The miniemulsion polymerization was quite fast, reaching high final conversion within $4 \mathrm{~h}$ (Figure S2.a and Table S2). ${ }^{[22]}$ During polymerization the number of droplets/ nanoparticles slightly increased, while the hydrodynamic diameter decreased from 76 to 63 nm (Figure S2.b). Transmission electron microscopy (TEM) analysis of the final samples confirmed dynamic light scattering (DLS) results and showed the formation of spherical nanoparticles that are quite homogeneous in size (Figure 1). As expected, their dimension in the dry state (TEM) is slightly smaller than the hydrodynamic radius $D_{\mathrm{h}}$ determined by DLS in aqueous dispersion.

It should be emphasized that the established miniemulsion polymerization process was reproducible (cf. FNP1 and FNP2 Figures 1 and S4, Tables S1 and S2). In contrast to the co-solvent method, FNP's synthesis could be conducted at high solids content (14\%) yielding 
concentrated particle suspensions, and on a shorter time scale because there is only two steps in the process.

In order to characterize the growing polymer chains, samples were withdrawn regularly during polymerization, dried and analyzed by size exclusion chromatography (SEC) in THF solution after methylation of the carboxylates. The SEC traces of the macroRAFT agents and copolymers obtained at different stages of the polymerization are displayed in Figure 2. It shows narrow symmetric peaks that are shifted towards shorter retention volumes (corresponding to longer polymer chains) upon progressing polymerization. The determined number-average molar masses, $M_{\mathrm{n}}$, increase linearly with monomer conversion and are close to the theoretical values, and polydispersity indexes, $M_{\mathrm{w}} / M_{\mathrm{n}}$, are low $(<1.3$, cf. Table S2). The miniemulsion copolymerization of styrene with fluorescent monomer exhibits thus the features of a living well-controlled polymerization.

Noteworthy, in the SEC chromatograms the UV-VIS signals at $\lambda=528 \mathrm{~nm}$ (maximum absorption of BDPMA) overlay with the RI signals, emphasizing that BDPMA is incorporated in all polymer chains (Figure S3). As expected the BDPMA conversion is faster than that of styrene (Figure S2.a and Table S2), which may be explained by the different reactivity ratios of the monomers (cf. phenyl methacrylate $(\Phi \mathrm{MA})$ and styrene $(\mathrm{S})$ : $\mathrm{r}_{\Phi \mathrm{MA} / \mathrm{S}}=$ $\left.0.51, \mathrm{r}_{\mathrm{S} / \mathrm{\Phi MA}}=0.25^{[23]}\right)$. Polymer chains should thus possess a gradient composition of BDPMA. Given that the FNPs consist of self-assembled amphiphilic triblock copolymers, more fluorescent monomers should therefore be located in the external part of the hydrophobic core.

Fluorescence and absorption spectroscopy analysis of FNP2 are displayed on Figure 3. The BDPMA monomer in toluene shows standard spectra for BODIPY fluorophores ${ }^{[13]}$ with an intense band in the visible region located at $528 \mathrm{~nm}$ (corresponding to a $\pi \rightarrow \pi^{*}$ transition) and a vibrational shoulder at higher energy. A second, less intense band is located in the UV region at around $380 \mathrm{~nm}$. The maximum of fluorescence emission is found at 540 
$\mathrm{nm}$, exhibiting a Stokes shift of $12 \mathrm{~nm}$. The fluorescent nanoparticles (FNP2) exhibit very similar absorption and fluorescence spectra with a maximum absorption at $529 \mathrm{~nm}$ and a maximum of fluorescence emission at $544 \mathrm{~nm}$. The Stokes shift of the nanoparticles $(15 \mathrm{~nm})$ is slightly higher than the monomer. This might be explained by the difference of polarity between the monomer in toluene and in a polystyrene matrix. One can also notice that the FNP2 absorption spectra exhibit a more intense vibrational shoulder which might result from the light scattered by the FNP or a more rigid environment (PS vs. toluene). The excitation spectra for FNP2 and monomer have the same aspect and superimpose virtually to their respective absorption spectra (Figure S5), showing that the absorbing and emitting species are identical.

Fluorescence quantum yield of FNP2 is $20 \%$ while that of BDPMA in toluene is $69 \%$. The decrease may be due to quenching between closely associated BDPMA monomers in the polystyrene matrix. As mentioned previously, BDPMA reacts more rapidly than styrene resulting in polymer chains composed of a BODIPY gradient which may favour formation of non emitting aggregates of the fluorophores. To confirm this hypothesis, we analyzed the linear methylated tribloc copolymers PEO- $b$-PAA- $b$-P(S-co-BDPMA) in toluene. The quantum yield found is $47 \%$. Since no BDPMA inter-chain interactions can happen with the linear copolymers, one can conclude that there is an extinction of fluorescence due to BODIPY aggregation along the polymer chain. The fluorescence decay of BDPMA in toluene (Figure 3, insert) is mono exponential (lifetime $\tau_{\mathrm{F}}=4.9 \mathrm{~ns}$ ) as expected for a fluorophore in diluted solution. In contrast, the fluorescence decay of FNP2 is best fitted by the sum of three exponential functions. This complex behaviour may again result from the presence of fluorophore-rich domains leading to their aggregation in the nanoparticles.

Finally, the pH-responsive behaviour of the fluorescent nanoparticles (FNP) has been investigated. Indeed, thanks to their PEO- $b$-PAA shell, the aqueous FNP suspension start to flocculate at $\mathrm{pH}$ below 6 (Figure S6). Interestingly, after precipitation (Figure 4), they can be 
easily re-dispersed in neutral to basic media without alteration of their structure since their hydrodynamic diameter remains nearly unchanged (Figure S7 and Table S3). This process can be repeated at least four times (Figure S9). Those properties are the key to an easy purification, recycling and concentration process: by precipitating the particles in acid media, one can remove the acid supernatant with the soluble impurities and replace it by a clean neutral to basic solution (Figure 4.c and d) with minimal loss of weight (approx 15\%). For biological applications the nature of the dispersion media (salts, ions, proteins...), can be easily exchanged. As an example, we centrifugated the FNP under acid media and redispersed it in a phosphate buffered saline $1 \times$ solution (Figures S7 and S8, Table S3). At last, it can be useful process to concentrate the fluorescent nanoparticles for further application.

\section{Conclusion}

A straightforward synthesis pathway to reach aqueous dispersions of fluorescent organic nanoparticles, in which the fluorophore is covalently linked to a polymer chain, has been developed. It relies on the use of amphiphilic negatively charged, macroRAFT agents and a one-pot miniemulsion polymerization process, where a BODIPY-methacrylate is copolymerized with styrene. Monodisperse nanoparticles, composed of well-defined individual amphiphilic polymer chains are formed, with a fluorescent core made of poly(S-coBDPYMA) and stabilized by a PEO- $b$-PAA shell. The developed method does not require the use of any ultra-hydrophobic agents or surfactants that may be contaminant for further application of the FNP. It was further shown that these particles precipitate in acidic $\mathrm{pH}$ without loss of their structure and can be easily redispersed in basic to neutral media for biological applications. Currently, the improvement of the fluorescence properties of the particles as well as the functionalization of the hydrophilic shell in order to convert these FNP into nanosensors is under way. 
Acknowledgements: We thank Patricia Beaunier (UPMC) for TEM imaging, and Gaëlle Pembouong, Arnaud Brosseau and Cédric Bonnafé for technical support.

Received: ((will be filled in by the editorial staff)); Revised: ((will be filled in by the editorial staff)); Published online: ((will be filled in by the editorial staff))

Keywords: block copolymers, BODIPY, core-shell polymers, micelles, stimuli-sensitive polymers

[1] a) N. L. Rosi, C. A. Mirkin, Chem. Rev. 2005, 105, 1547-1562; b) A. Louie, Chem. Rev. 2010, 110, 3146-3195; c) J. Hu, S. Liu, Macromolecules 2010, 43, 8315-8330.

[2] a) K. Ando, H. Kawaguchi, J. Colloid Interface Sci. 2005, 285, 619-626; b) J. Chen, F. Zeng, S. Wu, J. Su, Z. Tong, Small 2009, 5, 970-978; c) T. Tamai, M. Watanabe, H. Maeda, K. Mizuno, J. Polym. Sci. Part A: Polym. Chem. 2008, 46, 1470-1475; d) V. Holzapfel, A. Musyanovych, K. Landfester, M. R. Lorenz, V. Mailander, Macromol. Chem. Phys. 2005, 206, 2440-2449; e) M. R. Lorenz, M.-V. Kohnle, M. Dass, P.Walther, A. Höcherl, U. Ziener, K. Landfester, V. Mailänder, Macromol. Biosci. 2008, 8, 711-727; f) H. Gao, Y. Zhao, S. Fu, B. Li, M. Li, Colloid Polym. Sci. 2002, 280, 653-660; g) H. Furukawa, M. Misu, K. Ando, H. Kawaguchi, Macromol. Rapid Commun. 2008, 29, 547-551.

[3] K. Landfester, Macromol. Rapid Commun. 2001, 22, 896-936.

[4] A. Nagai, R. Yoshii, T. Otsuka, K. Kokado, Y. Chujo, Langmuir 2010, 26, 1564415649.

[5] a) J. You, J. A. Yoon, J. Kim, C.-F. Huang, K. Matyjaszewski, E. Kim, Chem. Mater. 2010, 22, 4426-4434; b) C. Li, Y. Zhang, J. Hu, J. Cheng, S. Liu, Angew. Chem. Int. Ed. 2010, 49, 5120-5124. 
[6] L. Zhang, A. Eisenberg, Science 1995, 268, 1728-1731.

[7] a) F. He, T. Gädt, M. Jones, G. D. Scholes, I. Manners, M. A. Winnik, Macromolecules 2009, 42, 7953-7960; b) J. Liu, D. Liu, Y. Yokoyama, S.-i. Yusa, K. Nakashima, Langmuir 2008, 25, 739-743.

[8] a) Sun, A. M. Scharff-Poulsen, H. Gu, K. Almdal, Chem. Mater. 2006, 18, 3381-3384;

b) L. Zhu, W. Wu, M.-Q. Zhu, J. J. Han, J. K. Hurst, A. D. Q. Li, J. Am. Chem. Soc. 2007, 129, 3524-3526; c) M. C. Baier, J. Huber, S. Mecking, J. Am. Chem. Soc. 2009, 131, 14267-14273.

[9] a) B. T. T. Pham, D. Nguyen, C. J. Ferguson, B. S. Hawkett, A. K. Serelis, C. H. Such, Macromolecules 2003, 36, 8907-8909; b) A. M. dos Santos, T. Le Bris, C. Graillat, F. D'Agosto, M. Lansalot, Macromolecules 2009, 42, 946-956; c) Y. Luo, H. Gu, Macromol. Rapid Commun. 2006, 27, 21-25; d) F. Lu, Y. Luo, B. Li, Macromol. Rapid Commun. 2007, 28, 868-874, e) B. T. T. Pham, H. Zondanos, C. H. Such, G. G. Warr, B. S. Hawkett, Macromolecules 2010, 43, $7950-7957$.

[10] J. H. Lee, H. B. Lee, J. D. Andrade, Progress Polym. Sci. 1995, 20, 1043-1079.

[11] C. Burguière, S. Pascual, C. Bui, J.-P. Vairon, B. Charleux, K. A. Davis, K. Matyjaszewski, I. Bétremieux, Macromolecules 2001, 34, 4439-4450.

[12] a) V. Sadtler, M. Rondon-Gonzalez, A. Acrement, C. Lionel, E. Marie, Macromol. Rapid Commun. 2010, 31, 998-1002; b) S. Fréal-Saison, M. Save, C. Bui, B. Charleux, S. Magnet, Macromolecules 2006, 39, 8632-8638.

[13] A. Loudet, K. Burgess, Chem. Rev. 2007, 107, 4891-4932.

[14] a) Y. Kajiwara, A. Nagai, Y. Chujo, J. Mater. Chem. 2010, 20, 2985-2992; b) F. AmatGuerri, M. Liras, M. L. Carrascoso, R. Sastre, Photochem. Photobiol. 2003, 77, 577-584; c) F. López Arbeloa, J. Bañuelos Prieto, I. López Arbeloa, A. Costela, I. García-Moreno, C. Gomez, F. Amat-Guerri, M. Liras, R. Sastre, Photochem. Photobiol. 2003, 78, 30-36.

[15] A. Nagai, K. Kokado, J. Miyake, Y. Chujo, Macromolecules 2009, 42, 5446-5452. 
[16] C. Dumas-Verdes, F. Miomandre, E. Lépicier, O. Galangau, T. T. Vu, G. Clavier, R. Méallet-Renault, P. Audebert, Eur. J. Org. Chem. 2010, 2525-2535.

[17] J. Lai, T. Filla, R. Shea, Macromolecules 2002, 35, 6754-6756.

[18] J. Rieger, F. Stoffelbach, C. Alaimo, C. Jerome, B. Charleux, Macromolecules 2008, 41, 4065-4068.

[19] L. Couvreur, B. Charleux, O. Guerret, S. Magnet, Macromol. Chem. Phys. 2003, 204, $2055-2063$

[20] J. Rieger, F. Stoffelbach, C. Alaimo, C. Jerome, B. Charleux, Macromolecules 2008, $41,4065-4068$.

[21] A triblock PEO- $b$-PAA13- $b$-PS25 has also been prepared and used for further poly(styrene-co-BDPMA) miniemulsion polymerization. The obtained FNP have the same characteristics in terms of number-average molecular mass and size as FNP1 and 2.

[22] Since styrene conversion was determined by gravimetry, it may be underestimated because approximately $10-15 \%$ of styrene is lost by evaporation after the bulk polymerization and ultra-sonic treatment.

[23] J. Brandrup, E. H. Immergut, E. A. Grulke, A. Abe, D. R. Bloch, Polymer Handbook, 4th ed., John Wiley \& Sons, 2005. 


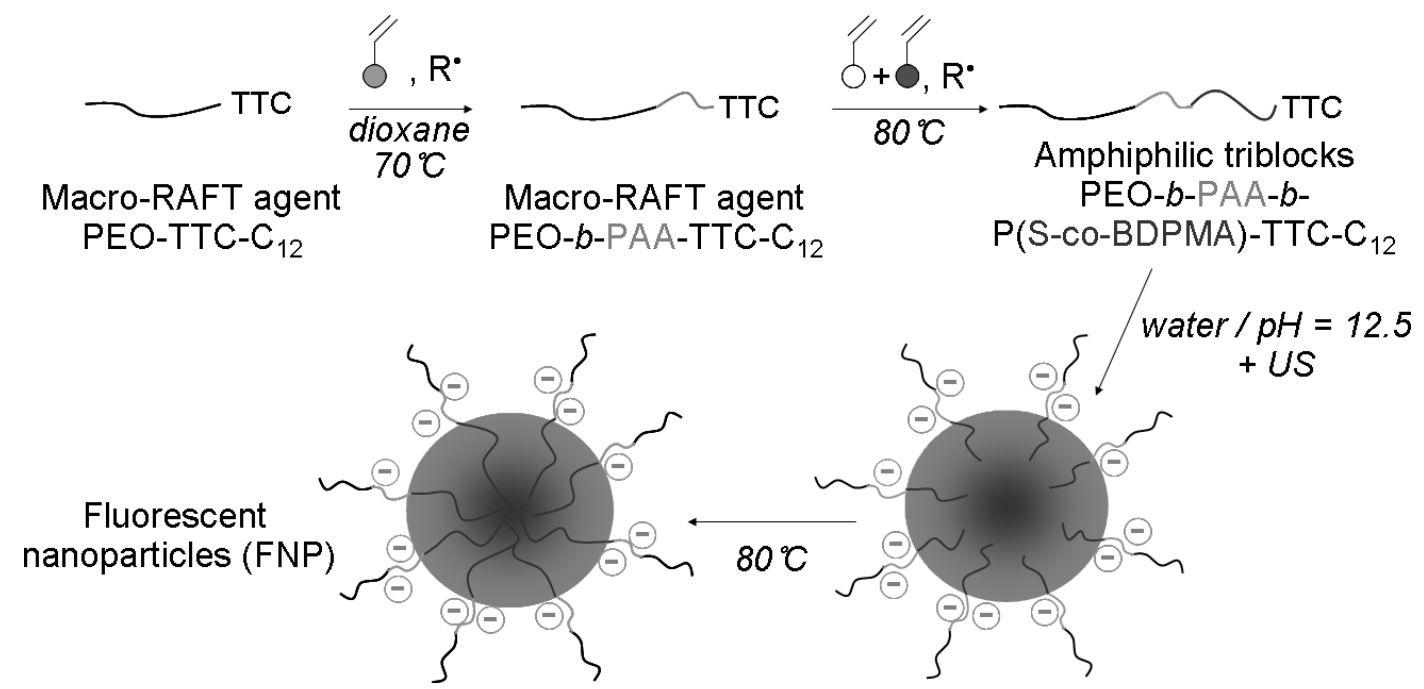

Scheme 1. Synthetic pathway employed for the synthesis of the fluorescent nanoparticles (see text for abbreviations' definitions.

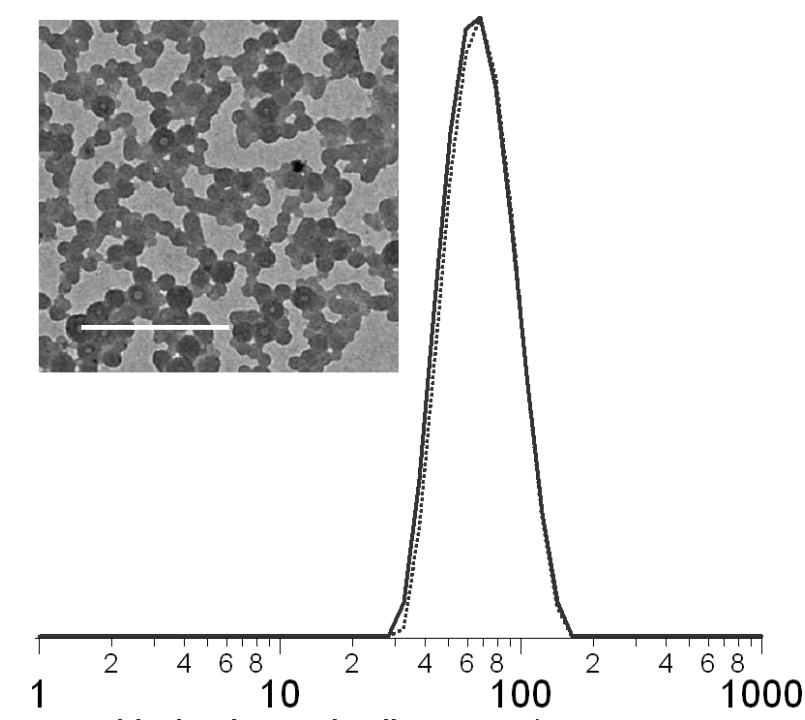

Hydrodynamic diameter / $\mathrm{nm}$ 1000

Figure 1. Normalized FNP1 (dotted lines) and FNP2 (full lines): dynamic light scattering signals in water $(\mathrm{pH} 9)$ and transmission electron microscopy photo of the dried nanoparticles (insert, scale bar: $400 \mathrm{~nm}$ ). 


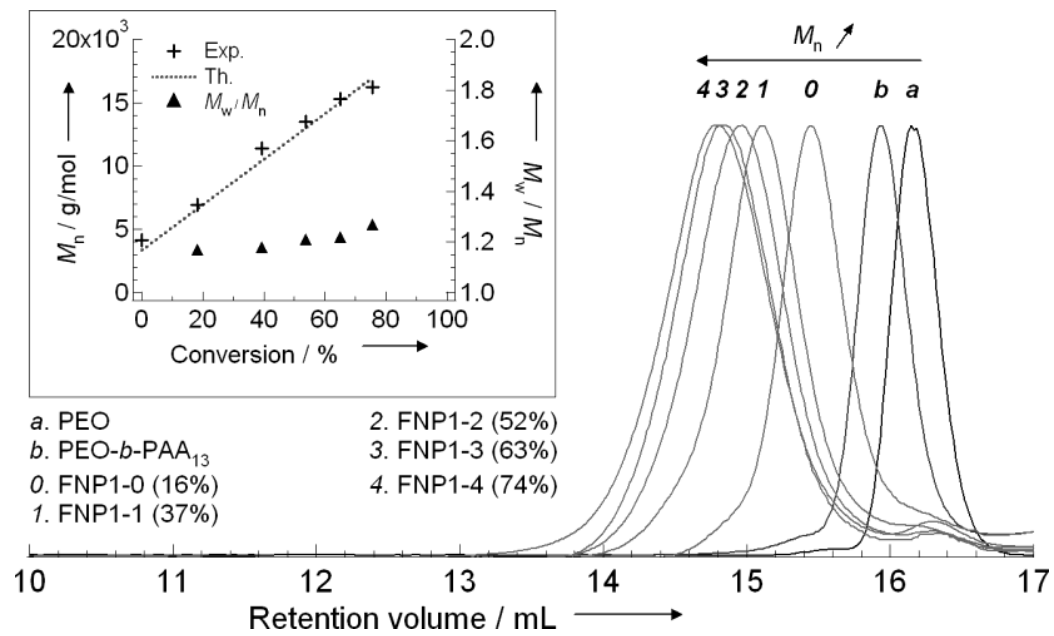

Figure 2. Normalized size exclusion chromatograms (RI signal) in THF for macroRAFT agents and FNP1, at different monomer conversions, and (insert) evolution of the numberaverage molar mass $\left(M_{\mathrm{n}}\right.$, PS calibration) and $M_{\mathrm{w}} / M_{\mathrm{n}} v s$. monomer conversion. The straight line corresponds to the theoretical $M_{\mathrm{n}}$ values (Equation S5).

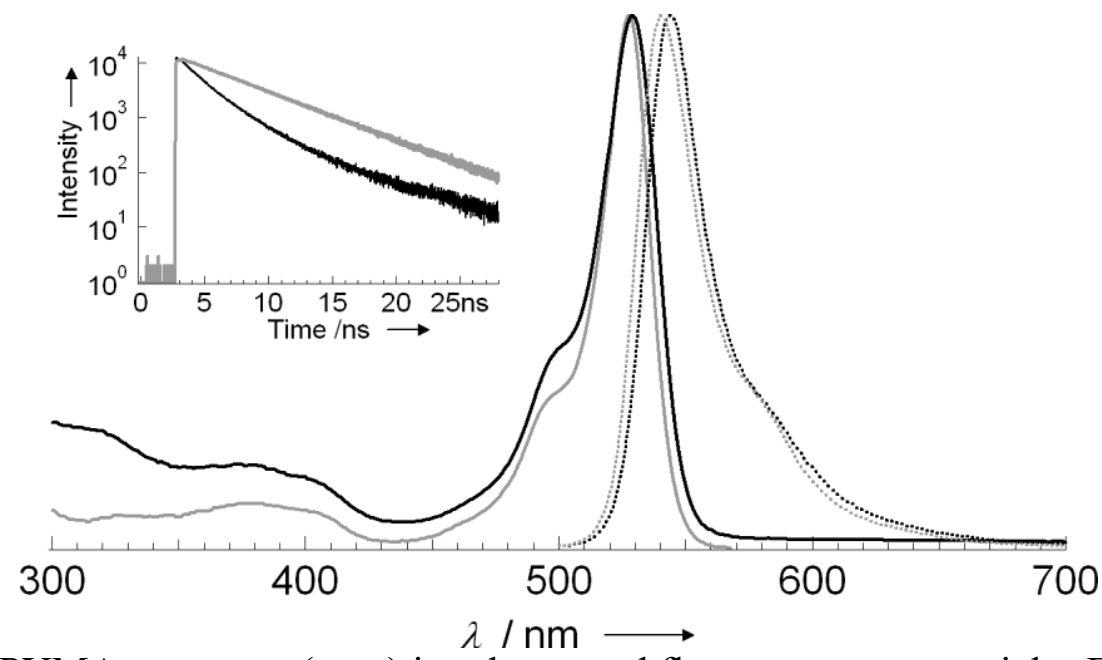

Figure 3. BDPYMA monomer (grey) in toluene and fluorescent nanoparticles FNP2 (black) in water $(\mathrm{pH}=9)$ : absorption (full lines) and fluorescence emission (dotted lines) normalized spectra and (insert) time resolved fluorescence decays. 


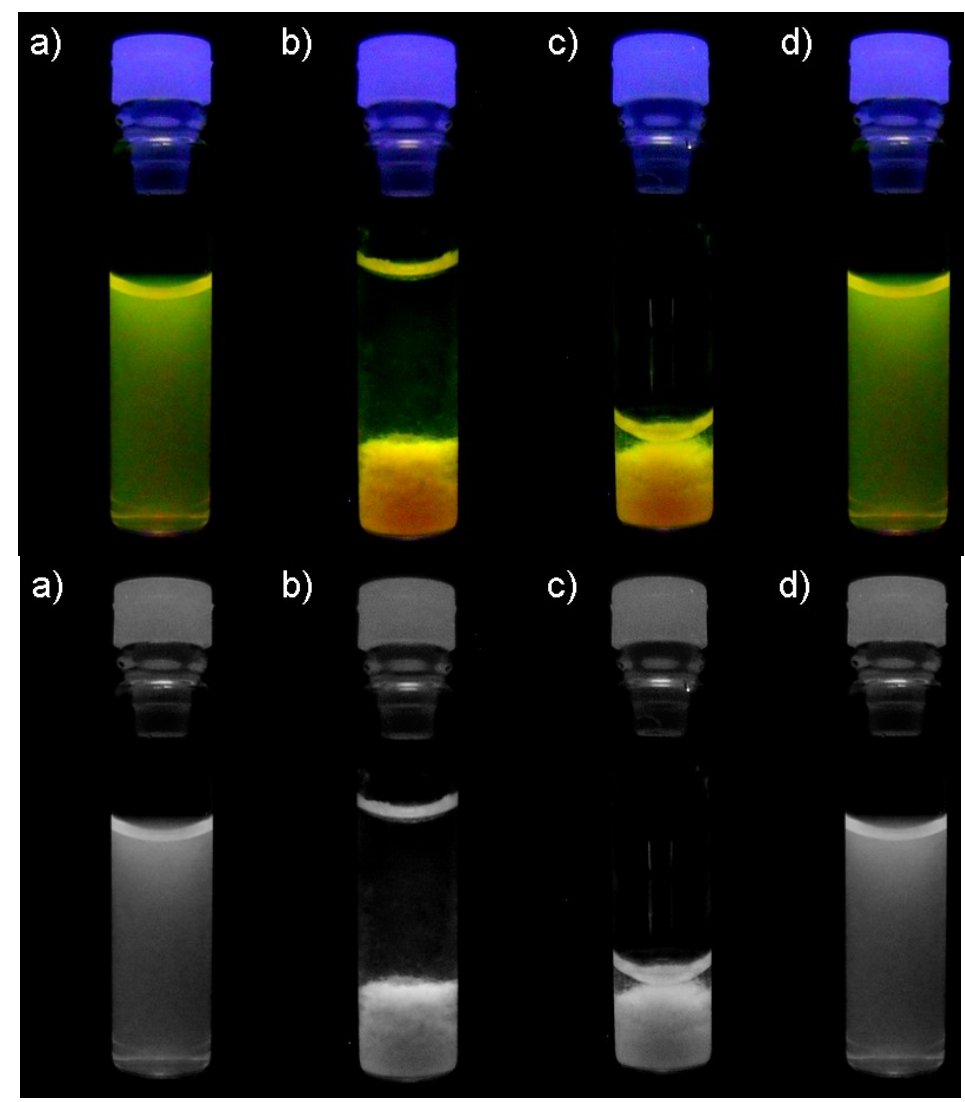

Figure 4. pH-Controlled precipitation/flocculation of FNP at $0.2 \%$ solid rate: a) FNP dispersed at $\mathrm{pH} 12.5 \mathrm{~b}$ ) FNP precipitated by addition of few drops of $1 \mathrm{M} \mathrm{HCl}$ solution ( $\mathrm{pH}$ 1.5) c) removal of supernatant d) FNP redispersed by addition of few drops of $1 \mathrm{M} \mathrm{NaOH}$ solution ( $\mathrm{pH} 12.5)$. 


\section{Material for the Table of contents}

Aqueous dispersions of fluorescent polystyrene nanoparticles are synthesised in one pot from an amphiphilic triblock polymer and a polymerizable fluorophore by a straightforward combination of miniemulsion and RAFT polymerization. No additional surfactant or hydrophobic agent are needed in the synthesis process. The nanoobjects display intense fluorescence as well as reversible sensitivity to $\mathrm{pH}$ (see picture).

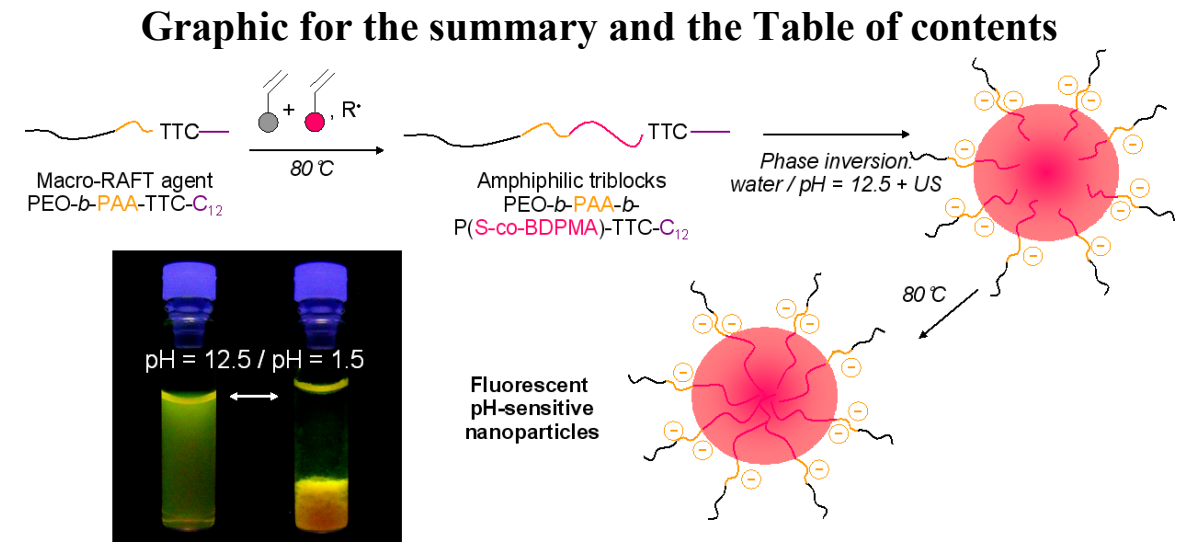

Chloé Grazon, Jutta Rieger, Rachel Méallet-Renault, Gilles Clavier*, Bernadette Charleux*

One-pot Synthesis of Pegylated Fluorescent Nanoparticles by RAFT Miniemulsion Polymerization using a Phase Inversion Process 
Copyright WILEY-VCH Verlag GmbH \& Co. KGaA, 69469 Weinheim, Germany, 2010.

\section{Supporting Information}

for Abbrev. J. Title, DOI: 10.1002/((please add journal code and manuscript number))

One-pot Synthesis of Pegylated Fluorescent Nanoparticles by RAFT Miniemulsion Polymerization using a Phase Inversion Process

Chloé Grazon, Jutta Rieger, Rachel Méallet-Renault, Gilles Clavier*, Bernadette Charleux*

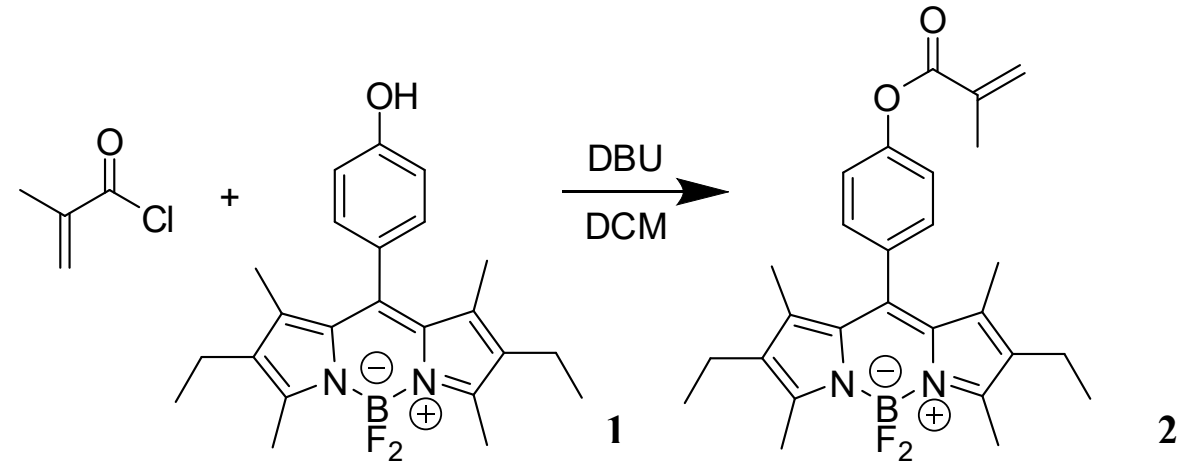

Scheme S1. Synthetic scheme employed for the synthesis of the fluorescent monomer BODIPY methacrylate (BDPMA).

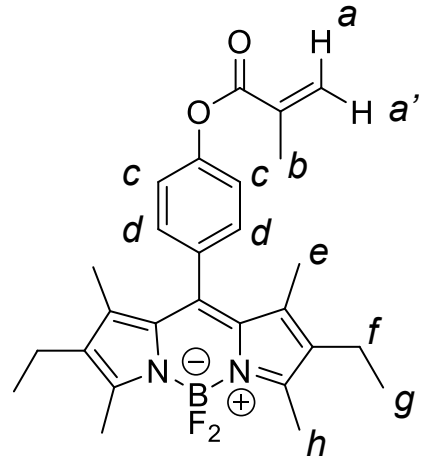

$$
c+d
$$

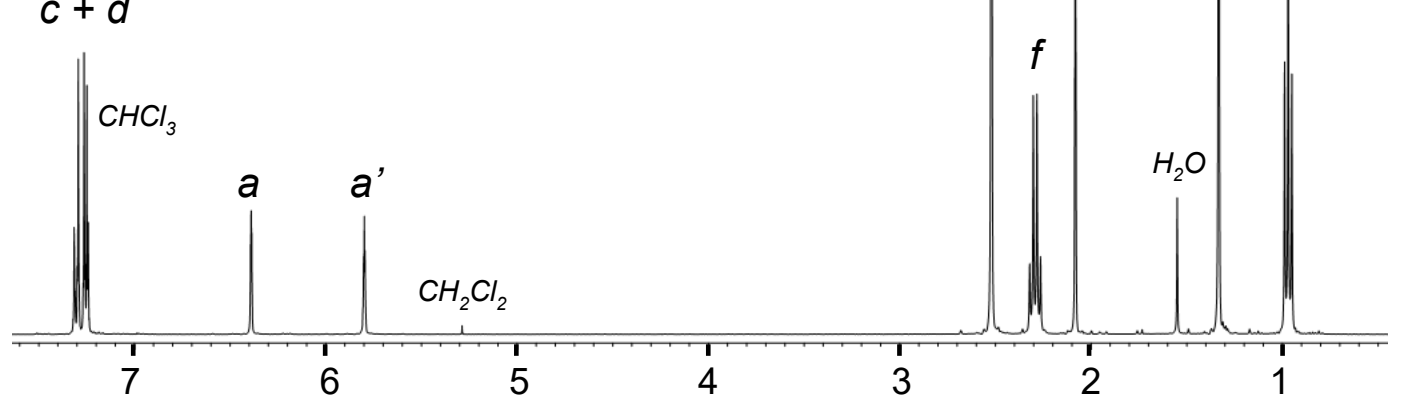

\section{$\delta / \mathrm{ppm}$}

Figure S1. ${ }^{1} \mathrm{H}$ NMR spectrum of BODIPY methacrylate (BDPMA) monomer recorded in $\mathrm{CDCl}_{3}$. 
<smiles>[X]C(COC(=O)C(C)(C)SC(=S)SCCCCCOC)(OCC)OCCOC</smiles>

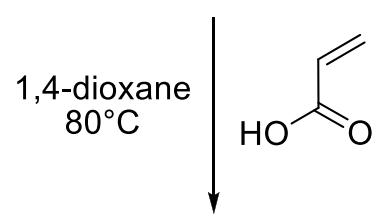

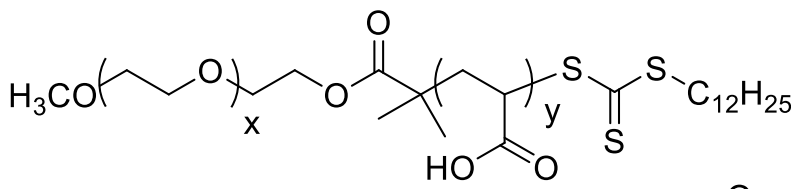

1. Bulk polymerization

2. Water added + US Miniemulsion polymerization $80^{\circ} \mathrm{C}$

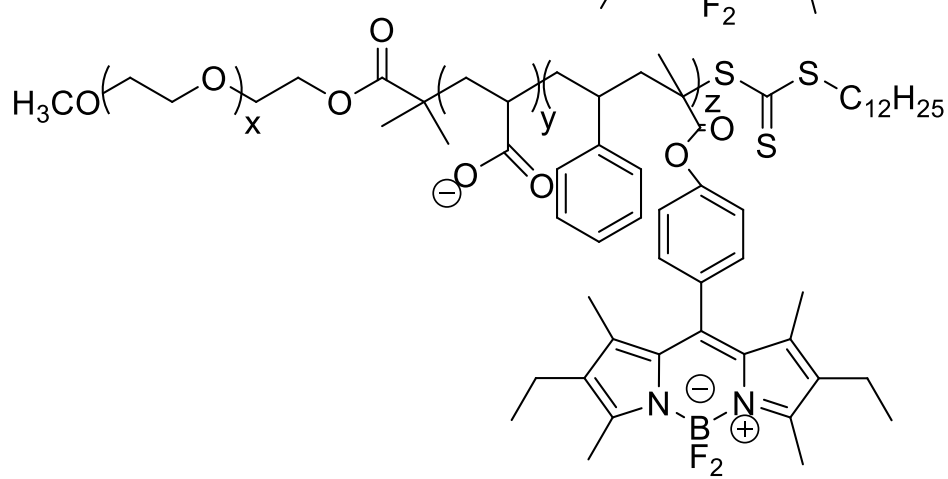

PEO $_{\mathrm{X}}-\mathrm{TTC}^{-\mathrm{C}_{12}}$

PEO $_{x}-b-$ PAA $_{y}-$ TTC- $_{12}$

Scheme S2. Synthetic scheme employed for the synthesis of the fluorescent nanoparticles (FNP1 and FNP2). 
Table S1. Polymerization conditions for two different batches of fluorescent nanoparticles, FNP1 and FNP2.

\begin{tabular}{|c|c|c|c|c|c|}
\hline sample & MacroRAFT agent & $D P_{n} t^{[a]}$ & $\begin{array}{c}\text { \%BDPMA } \\
/ \%^{[\mathrm{b}]}\end{array}$ & {$[\mathrm{M}] / \mathrm{mol}_{[\mathrm{c}]} / \mathrm{L}$} & $\begin{array}{c}\tau_{\mathrm{s}} / \\
\%^{[d]}\end{array}$ \\
\hline FNP1 & PEO-b-PAA $13-$ TTC-C $_{12}$ & 162 & 2.0 & 0.98 & 14 \\
\hline FNP2 & PEO- $b-\mathrm{PAA}_{10}-\mathrm{TTC}^{-\mathrm{C}_{12}}$ & 157 & 1.9 & 1.13 & 14 \\
\hline
\end{tabular}

[a] Theroritical number-average degree of polymerization for the P(S-co-BDPMA) block, [b] percent of BDPMA compare to styrene in mole: $\%$ BDPMA $=n_{B D P M A} /\left(n_{S}+n_{B D P M A}\right)$, [c] total monomer concentration, [d] solids content.
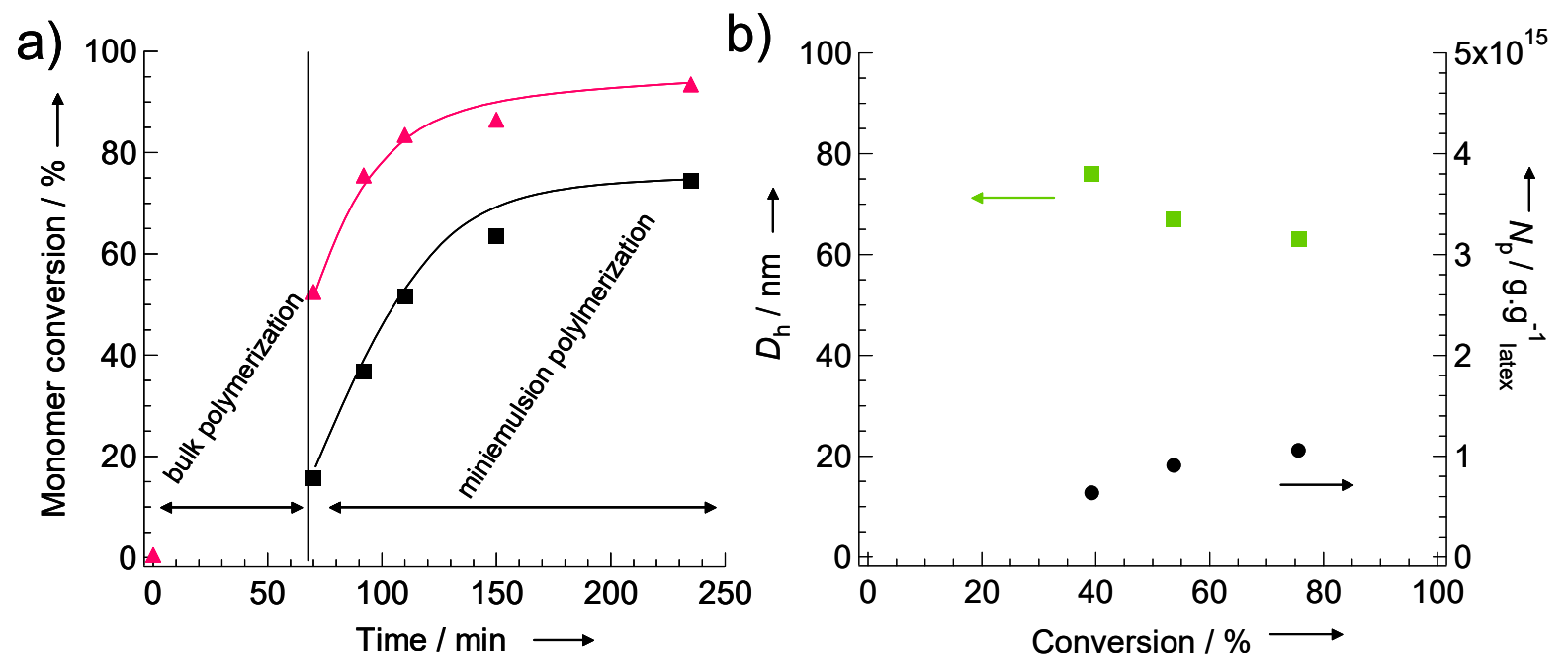

Figure S2. Synthesis of FNP1: (a) evolution of the BDPMA $(\boldsymbol{\Delta})$ and overall BDPMA and styrene ( $)$ molar monomer conversion with time and (b) evolution of the hydrodynamic diameter $\left(D_{\mathrm{h}}\right)$ of the particles $(\square)$ and particle number $\left(N_{\mathrm{p}}\right.$, Equation $\left.\mathrm{S} 6\right)(\bullet)$ with monomer conversion.

Table S2. Kinetic study of the synthesis of FNP1 and comparison with FNP2

\begin{tabular}{|c|c|c|c|c|c|c|c|c|}
\hline Sample & $\begin{array}{l}\text { Time } \\
/ \min \end{array}$ & $\begin{array}{c}\text { Styrene } \\
\text { conv. / \% [a] }\end{array}$ & $\begin{array}{l}\text { BDPMA conv. } \\
\qquad / \%^{[b]}\end{array}$ & $\begin{array}{c}\text { Monomer } \\
\text { mass conv. } \\
\quad / \%[c]\end{array}$ & $\begin{array}{c}M_{\mathrm{n} \text { th }} / \\
\mathrm{kg} / \mathrm{mol}[\mathrm{d}]\end{array}$ & $\begin{array}{l}M_{\mathrm{n}} \text { SEC I } \\
\mathrm{kg} / \mathrm{mol}{ }^{[\mathrm{e}]}\end{array}$ & $\begin{array}{c}M_{\mathrm{w}} / M_{\mathrm{n}} \\
\text { [e] }\end{array}$ & $\begin{array}{c}D_{\mathrm{h}} / \mathrm{nm} \\
(\sigma)^{[f]}\end{array}$ \\
\hline FNP1-0 & 70 & 15 & 52 & 18 & 6.7 & 6.9 & 1.16 & \\
\hline FNP1-1 & 92 & 36 & 75 & 39 & 10.4 & 11.4 & 1.17 & $76(0.25)$ \\
\hline FNP1-2 & 110 & 51 & 83 & 54 & 13.0 & 13.5 & 1.20 & $67(0.19)$ \\
\hline FNP1-3 & 150 & 63 & 86 & 65 & 15.0 & 15.3 & 1.21 & \\
\hline FNP1-4 & 235 & 74 & 93 & 76 & 17.0 & 16.3 & 1.26 & $63(0.16)$ \\
\hline FNP2 & 240 & 74 & 98 & 76 & 16.4 & 21.0 & 1.25 & $65(0.08)$ \\
\hline
\end{tabular}

[a] Styrene conversion is determined by gravimetry (Equation S1), [b] BDPMA conversion is determined by SEC (Equation S2), [c] overall mass conversion (Equation S4), [d] theoretical number-average molar mass $\left(M_{n}\right.$ th $)$ (Equation S5), [e] number-average molar mass $\left(M_{n}\right.$ SEC) and polydispersity index $\left(M_{\mathrm{w}} / M_{\mathrm{n}}\right)$ are determined by steric exclusion chromatography using a polystyrene calibration, [f] hydrodynamic diameter $\left(D_{h}\right)$ and dispersity factor $(\sigma)$ determined by DLS. 


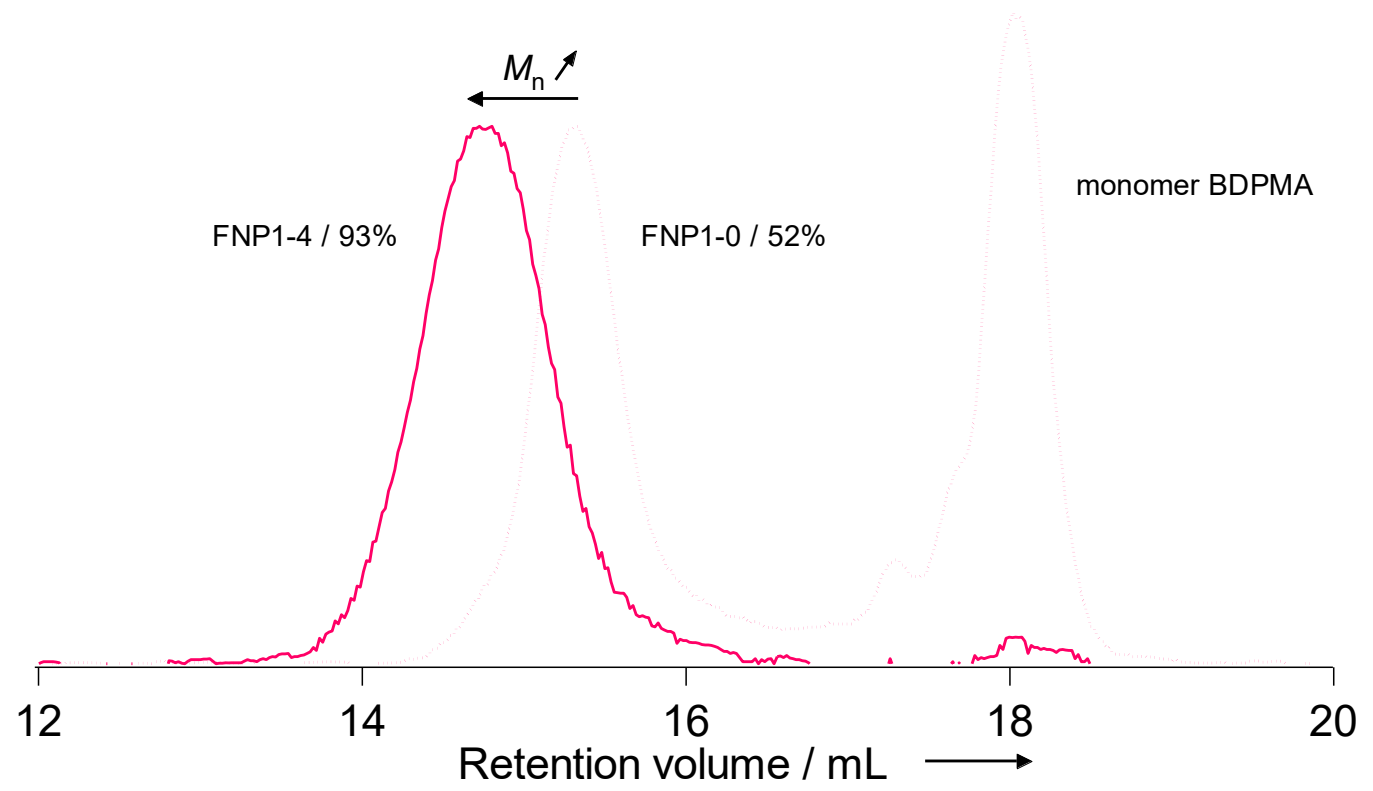

Figure S3. Normalized UV-vis. signals $(\lambda=528 \mathrm{~nm})$ of size exclusion chromatograms in THF: FNP1-0 (dotted lines) and FNP1-4 (full lines). The retention volume of the monomer BDPMA is at $18 \mathrm{~mL}$. The indicated percentages \% corresponds to the BDPMA conversion.

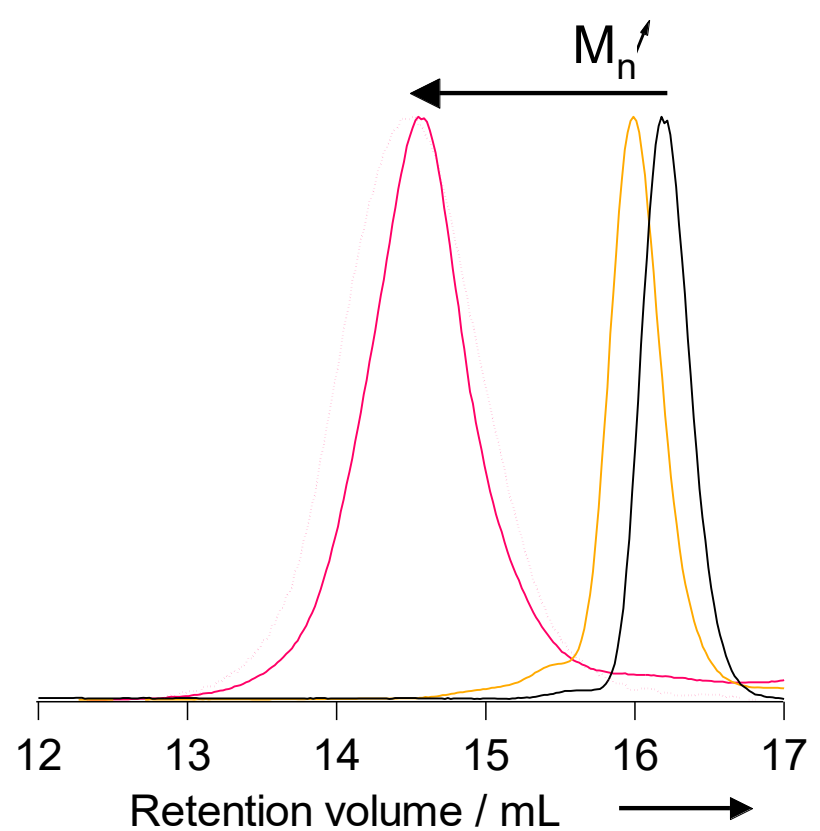

Figure S4. Normalized size exclusion chromatograms in THF: PEO-TTC-C12 (-),PEO-bPAA10 (-) and FNP2 (-). Full and dotted lines respectively stands for RI and UV-vis. signals $(\lambda=528 \mathrm{~nm})$. 


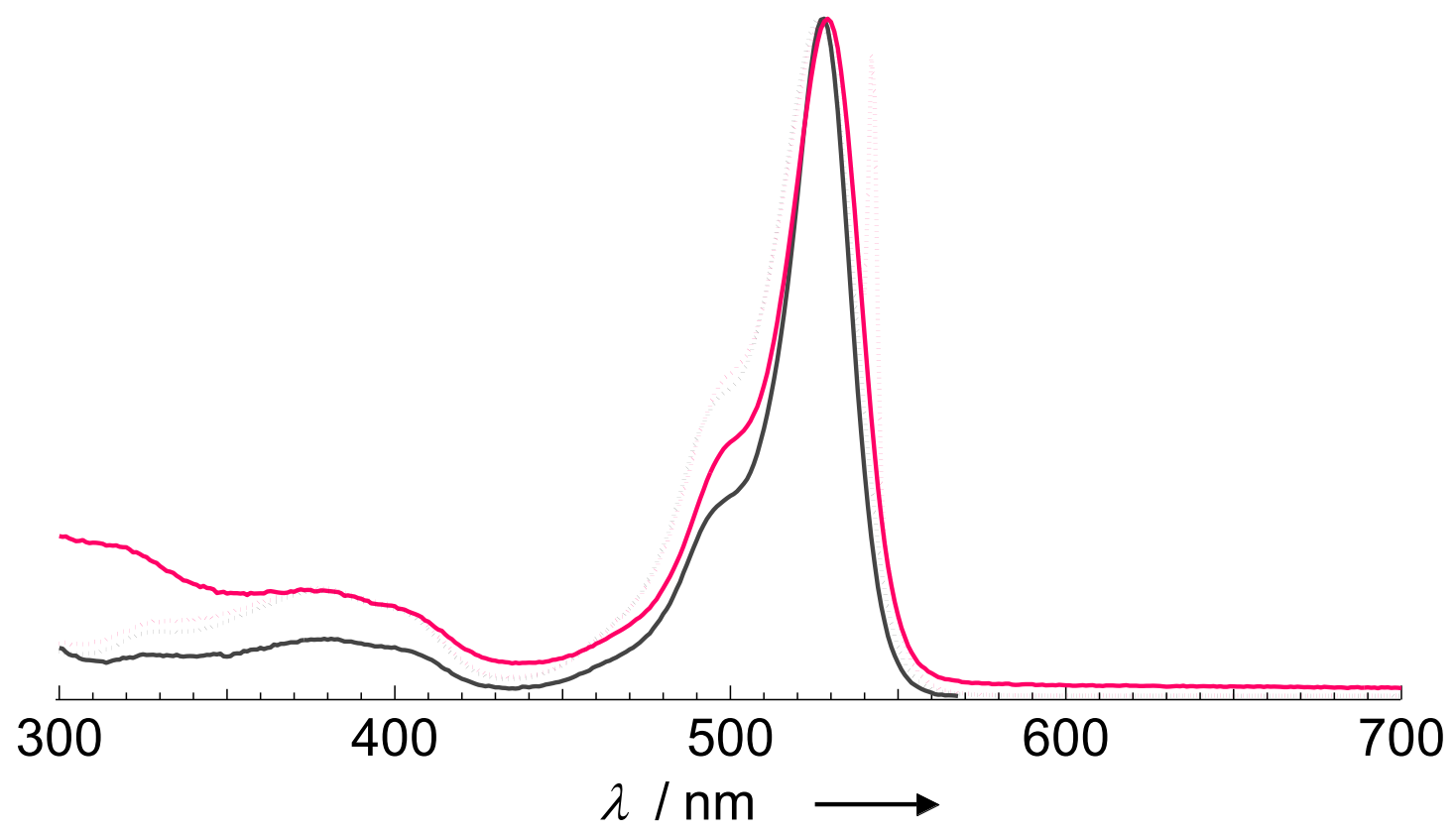

Figure S5. Normalized absorption (full lines) and excitation (dotted lines) spectra of BDPYMA monomer (-) in toluene and fluorescent nanoparticles FNP2 (-) in water.

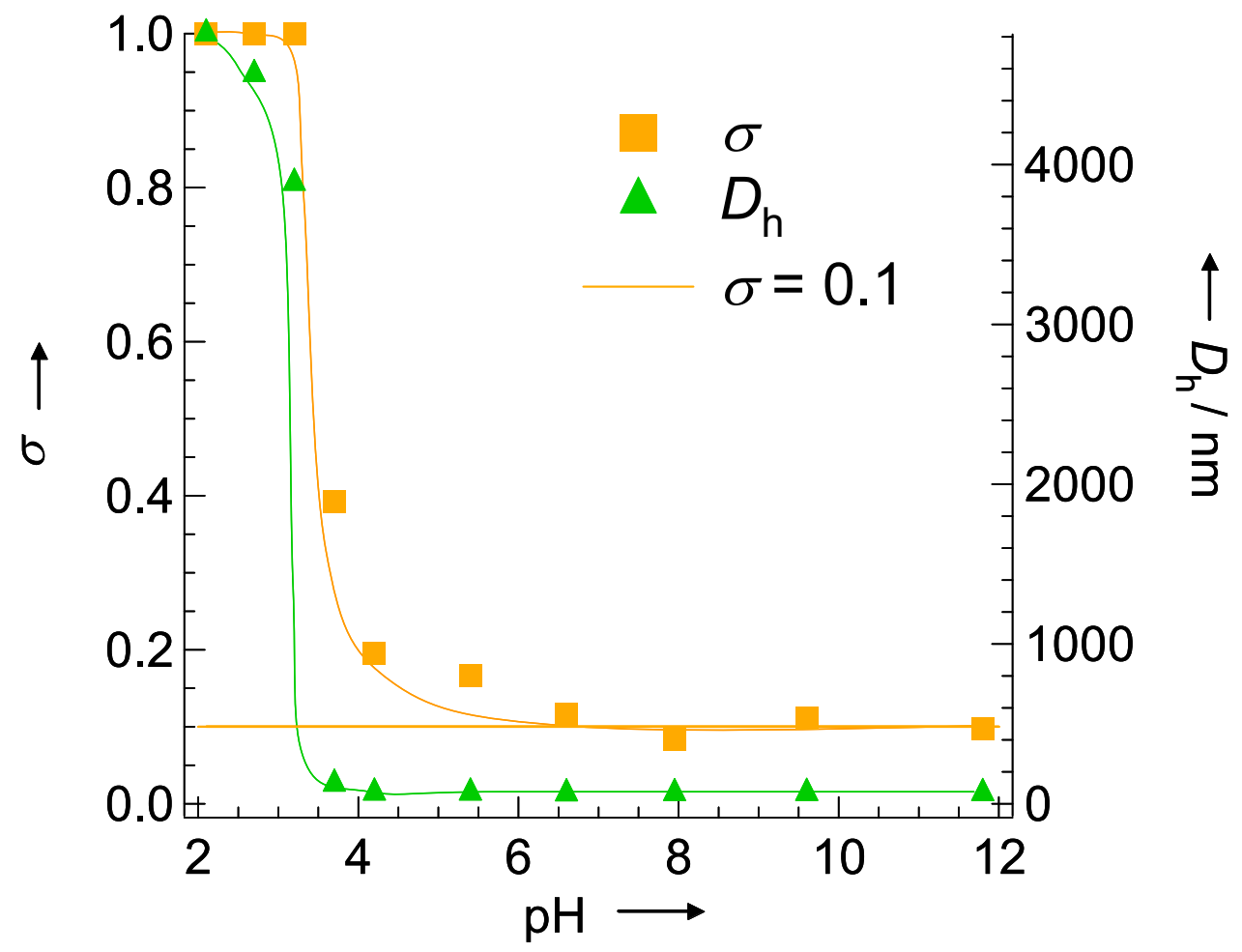

Figure S6. Evolution of the dispersity factor $(\sigma)$ and hydrodynamic diameter $\left(D_{\mathrm{h}}\right)$ of FNP2 with $\mathrm{pH}$. 


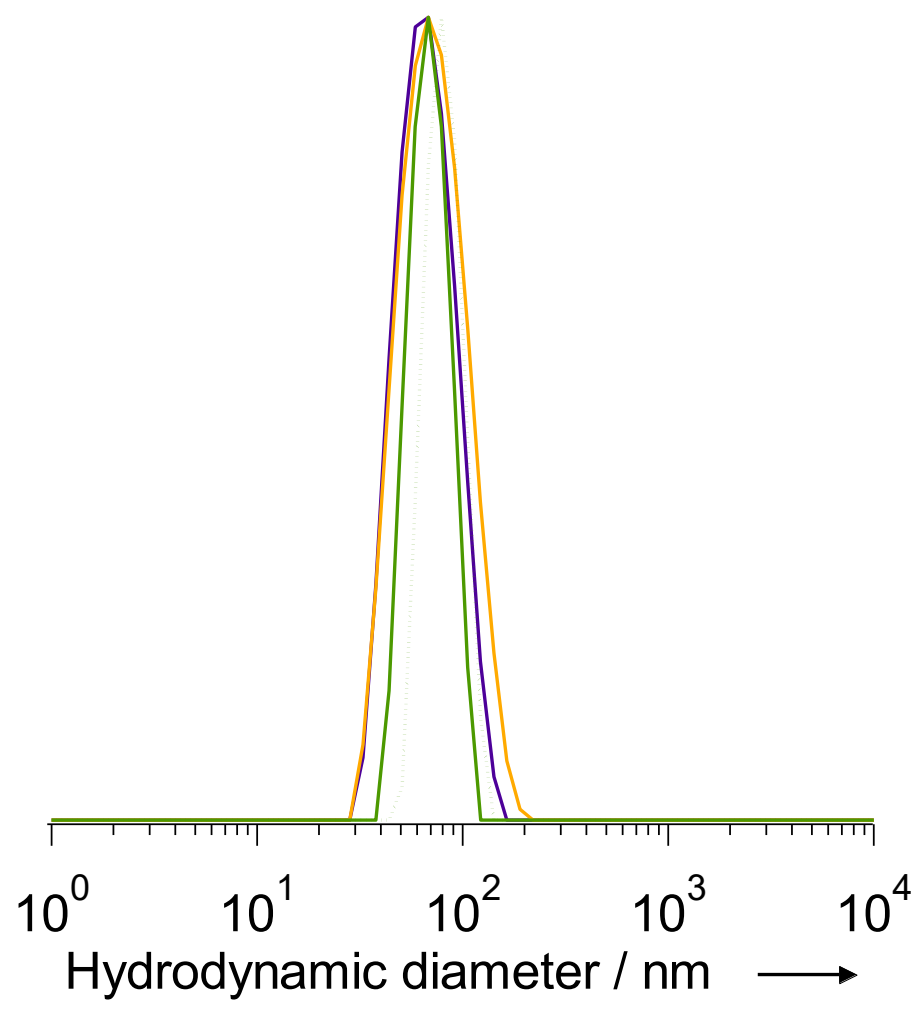

Figure S7. FNP2's hydrodynamic diameter at $\mathrm{pH}$ 12.5: after polymerization (-) ; after being firstly acidified with $\mathrm{HCl}(1 \mathrm{M})$ and then basicified with $\mathrm{NaOH}(1 \mathrm{M})$ to reach $\mathrm{pH} 12.5$. $(-)$; after being firstly acidified with $\mathrm{HCl}(1 \mathrm{M})$ and then redispersed in phosphate buffered saline $1 \times(\mathrm{pH} 7.4)(-)$ at $25^{\circ} \mathrm{C}$ (full line) and $37^{\circ} \mathrm{C}$ (dotted line).

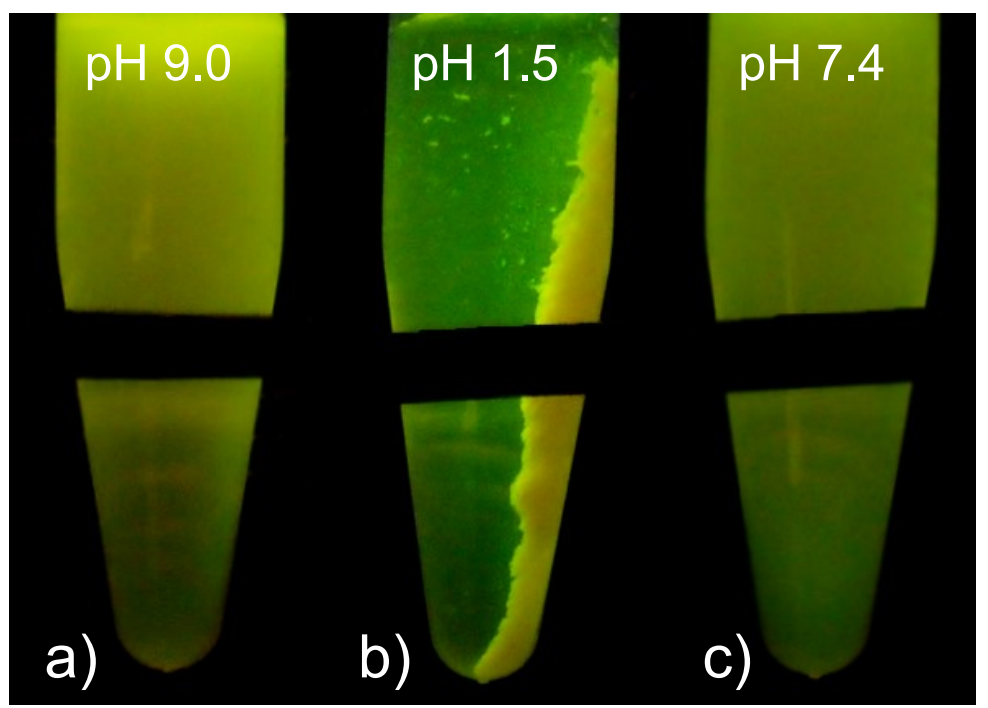

Figure S8. $\mathrm{pH}$-Controlled precipitation/flocculation of FNP at $0.2 \%$ solids content: a) FNP dispersed at $\mathrm{pH} 9 \mathrm{~b}$ ) FNP precipitated by addition of few drops of $1 \mathrm{M} \mathrm{HCl}$ solution ( $\mathrm{pH} 1.5)$ and centrifuged at $3000 \mathrm{rpm}$ for 2 minutes c) FNP redispersed in phosphate buffered saline $1 \times$ $(\mathrm{pH} 7.4)$. 
Table S3. Hydrodynamics diameters of FNP2 at different $\mathrm{pH}$ and temepratures

Dispersed solvent

pH Temperature $/{ }^{\circ} \mathrm{C}$ [a]

$D_{\mathrm{h}} / \mathrm{nm}^{[\mathrm{b}]}$

$\boldsymbol{\sigma}^{[\mathrm{b}]}$

FNP in water, after

12.5

20

65

0.08

polymerization

FNP in water, redispersed in

12.5

20

67.9

0.15

water after being acidified

FNP in PBS $1 \times$ after being

7.4

25

62.9

0.14

acidified and centrifugated

FNP in PBS $1 \times$ after being

$$
7.4
$$

37

76.9

0.09

acidified and centrifugated

[a] temperature used for light scattering analysis [b] hydrodynamic diameter $\left(D_{\mathrm{h}}\right)$ and dispersity factor ( $\sigma)$ determined by DLS.

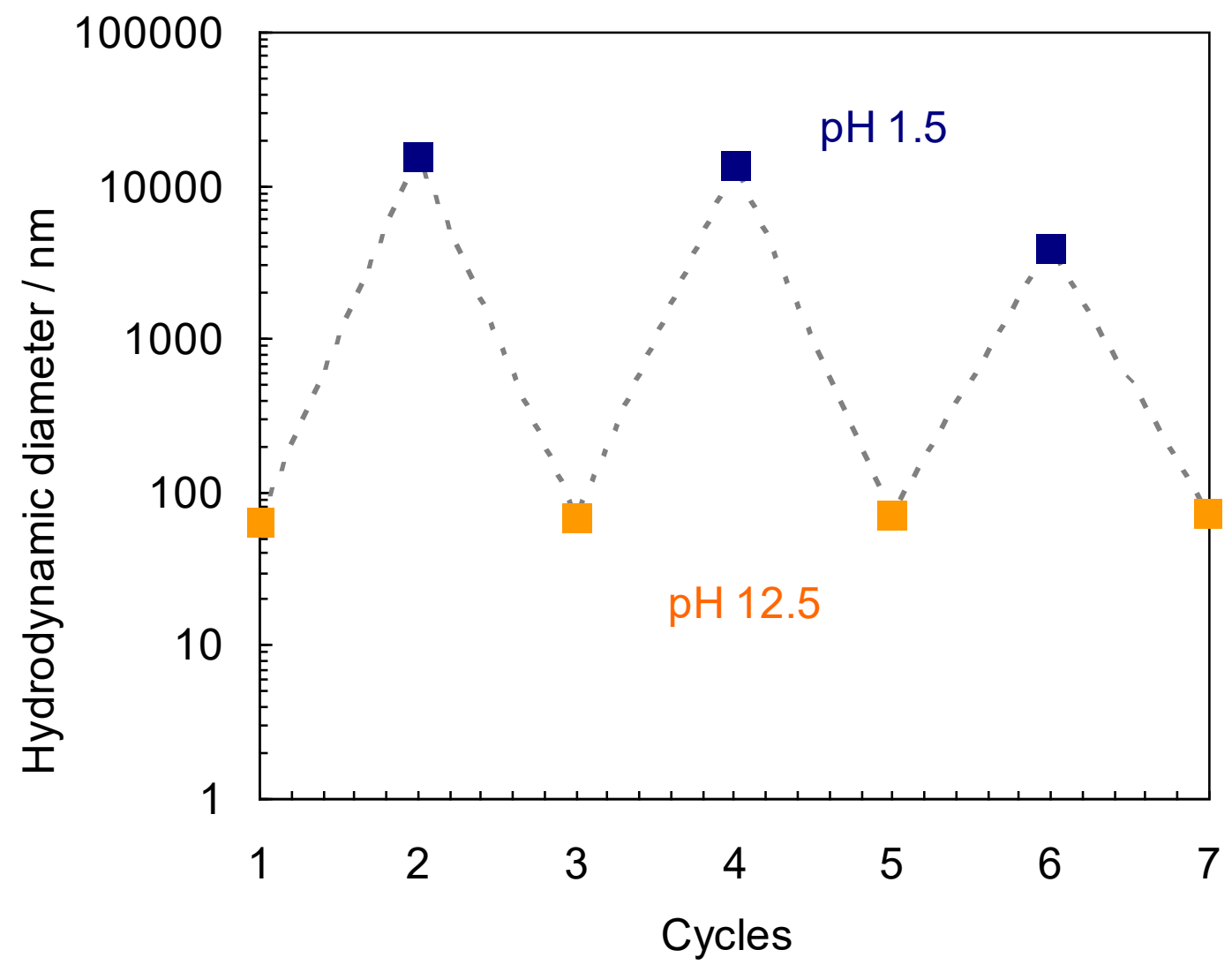

Figure S9. Variation of hydrodynamic diameter of the FNP as a function of $\mathrm{pH}$ cycles. 


\section{Equations}

Styrene (S) conversion

Styrene conversion was determined by gravimetry, using the following equation:

$$
x=\frac{\tau_{P S}}{\tau_{\text {styrene }}}=\frac{D E-\tau_{N V}}{\tau_{\text {styrene }}}
$$

Equation S1.

where

$\mid \begin{array}{ll}x & \text { styrene conversion } \\ \tau_{P S} & \text { experimental polystyrene (PS) content } \\ \tau_{\text {styrene }} & \text { initial styrene content (styrene mass at } t_{0} / \text { total mass) } \\ D E & \text { overall solids content } \\ \tau_{N V} & \text { non-volatile compounds content (without polystyrene) }\end{array}$

BODIPY methacrylate (BDPMA) conversion

BDPMA conversion was determined by SEC, UV-vis. detection $(\lambda=528 \mathrm{~nm}$, abs. max of BDPMA) comparing the integration of the monomer (BDPMA) and copolymer (PEO- $b$-PAA$\mathrm{P}(\mathrm{S}-c o-\mathrm{BDPMA})-\mathrm{TTC}-\mathrm{C}_{12}$ traces. To do so, we assumed that $\varepsilon_{\text {monomer }}^{528} \approx \varepsilon_{\text {polymer }}^{528}$. This assumption appears acceptable since the photophysical properties of BODIPY chromophores are known to be weakly affected by their environment. Hence BDPMA conversion was determined as:

$$
y=\frac{S_{P B D P M A}}{S_{P B D P M A}+S_{B D P M A}}
$$

where

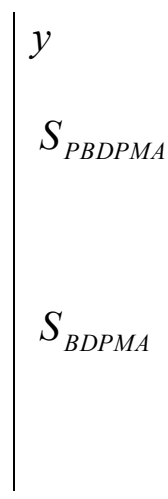

BDPMA conversion

Equation S2.

where

integration of the UV-vis. signal corresponding to the

polymerized BDPMA (PBDPMA)

integration of the UV-vis. signal corresponding to the

BDPMA monomer $(\mathrm{MW}=464 \mathrm{~g} / \mathrm{mol})$ 
Overall molar conversion

$$
z_{n}=x \cdot \frac{n_{S}}{n_{T}}+y \cdot \frac{n_{B D P M A}}{n_{T}}
$$

where

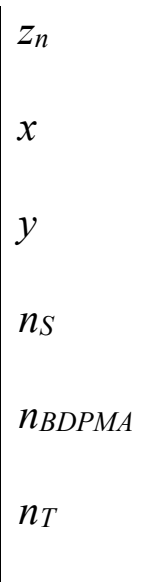

Overall mass conversion

where

$\mid \begin{aligned} & z_{m} \\ & x \\ & y \\ & m_{S} \\ & m_{B D P M A} \\ & m_{T}\end{aligned}$

Equation S3.

monomer molar conversion

styrene conversion determined by gravimetry

BDPMA conversion determined by SEC

moles of styrene used in the polymerization

moles of BDPMA used in the polymerization

moles of styrene and BDPMA used in the polymerization $z_{m}=x \cdot \frac{m_{S}}{m_{T}}+y \cdot \frac{m_{B D P M A}}{m_{T}}$

Equation S4.

monomer mass conversion

styrene conversion determined by gravimetry

BDPMA conversion determined by SEC

mass of styrene used in the polymerization

mass of BDPMA used in the polymerization

mass of styrene and BDPMA used in the polymerization

Theoretical number-average molar mass $\left(M_{n}\right.$ th)

$$
M_{n} t h=M_{n C T A}+\frac{1}{n_{C T A}}\left(x \cdot m_{S}+y \cdot m_{B D P M A}\right)
$$


where

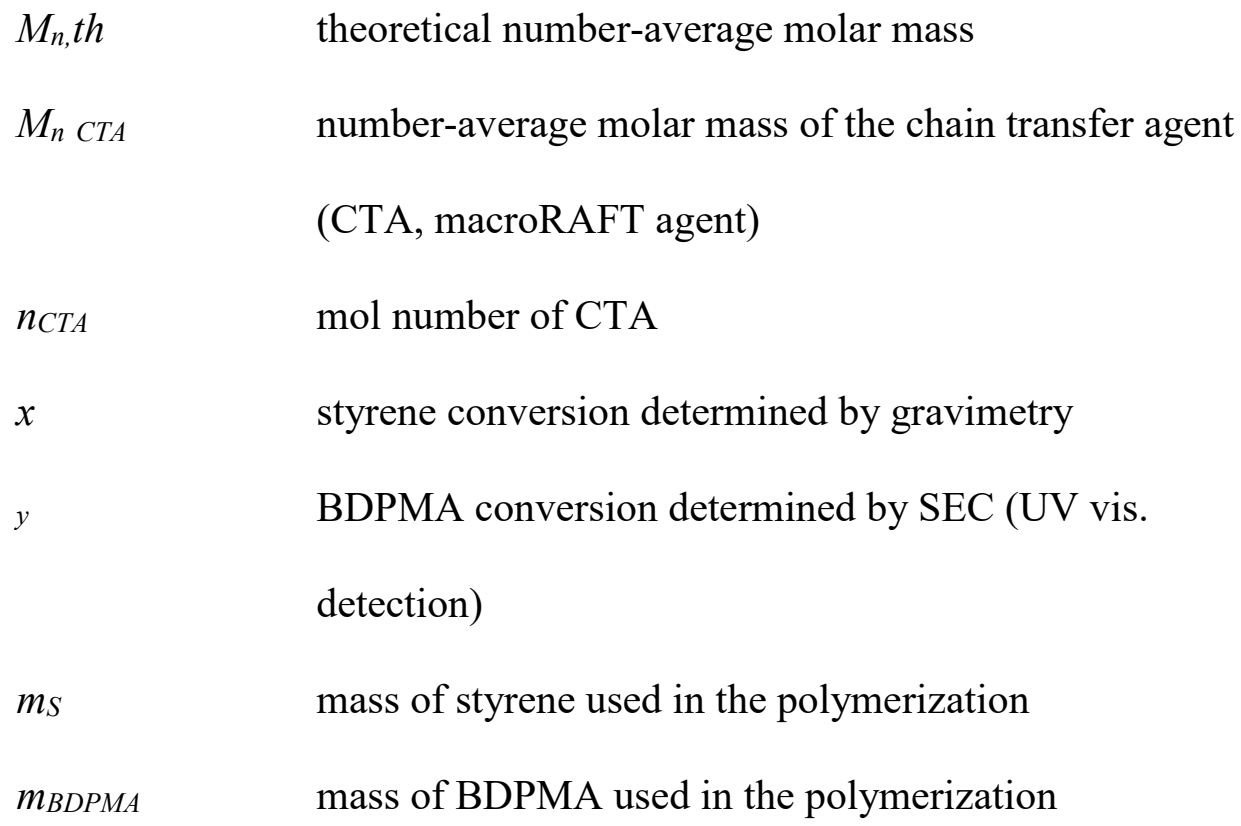

Particles number

$$
N p=\frac{6 \tau_{s}}{\pi D_{h}{ }^{3} \cdot\left(\rho_{P S} \cdot x+\rho_{S} \cdot(1-x)\right)}
$$

where / total mass)

$D_{h} \quad$ hydrodynamic diameter

$\rho s$

styrene density $(0.91 \mathrm{~g} / \mathrm{mL})$

polystyrene density $(1.05 \mathrm{~g} / \mathrm{mL})$

styrene conversion 